\title{
AvaliaçÃo NeUropsicológica: UM ESTUDO DA AVALIAÇÃO QUALITATIVA NA PRÁTICA
}

Milena Vasconcelos Martins de Jesus

O presente estudo tem como objetivo averiguar a importância da avaliação qualitativa na prática de 11 psicólogos que realizam a avaliação neuropsicológica. Os dados obtidos, por meio de entrevistas semiestruturadas, foram organizados em princípios de classificação e conjuntos de categorias que, ao serem analisados, permitiram concluir que a importância dada pelos neuropsicólogos à avaliação qualitativa ainda está muito aquém da avaliação quantitativa.

BANCA:

Monah Winograd (Orientadora)

Flavia Sollero de Campos

Rosinda Martins Oliveira

Data da defesa: $12 / 04 / 2010$ 